\section{International Scientific Journal Theoretical \& Applied Science}

p-ISSN: 2308-4944 (print) e-ISSN: 2409-0085 (online)

Year: $2014 \quad$ Issue: $10 \quad$ Volume: 18

Published: $30.10 .2014 \quad$ http://www.T-Science.org
Anna Pavlovna Kononenko Associate Professor of philology, the Faculty of Humanities, Rostov State Transport University, Russia kononenkocap1@mail.ru

SECTION 29. Literature. Folklore. Translation Studies.

\title{
THE WAYS OF THE TRANSLATION OF THE SHORTENINGS FROM A FOREIGN LANGUAGE INTO RUSSIAN
}

\begin{abstract}
The article is considering the processes in development of the borrowed shortenings in the modern languages. The significance of this article can be proved by the following reasons: the borrowed shortening is one of the developing branches of lexicology nowadays, the borrowed shortening reflects the general trend of simplification of a language, the borrowed shortening is closely connected with the development of modern informational technologies, being a developing branch of linguistics.

Key words: borrowed shortening, borrowed graphical abbreviations, borrowed abbreviations, borrowed lexical abbreviations, acronyms, clippings, initial clipping, or aphesis.

Language: English Russian

Citation: Kononenko AP (2014) THE WAYS OF THE TRANSLATION OF THE SHORTENINGS FROM A FOREIGN LANGUAGE INTO RUSSIAN. ISJ Theoretical \& Applied Science 10 (18): 85-87. doi: http://dx.doi.org/10.15863/TAS.2014.10.18.18
\end{abstract}

\section{СПОСОБЫ ПЕРЕВОДА СОКРАЩЕННЫХ ЕДИНИЦ С ИНОСТРАННОГО ЯЗЫКА НА РУССКИЙ}

Аннотация: В статье говорится о процессах заимствованных сокращуений в современных языках. Уникальность данной статьи подтверждается следующчими причинами: заимствованное сокрашение является одним из развивающихся направлений в лексикологии, заимствованное сокращение влияет на упрощение языка, заимствованное сокращение связано с развитием современных информационных технологий.

Ключевые слова: заимствованное сокращение, заимствованные графические аббревиатуры, заимствованные аббревиатуры,заимствованные лексические аббревиатуры, акронимы, усечения,инициальные аббревиатуры.

На развитие и изменение значения слова влияют как законы языковой системы, так и внеязыковые изменения в жизни общества. И те и другие можно рассматривать как в диахронии, так и в синхронии; однако, учитывая, что момент вхождения в язык измененного значения редко бывает зафиксирован точно, а сам процесс переосмысления идет в языке практически непрерывно. Мы не будем отделять один план от другого, отметив лишь, что изменения значения слова обусловливаются различными потребностями языкового общества. Условно их можно разделить на две группы экстралингвистические (события, происходящие в жизни языковой общности) и лингвистические (связанные с процессами, происходящими внутри системы языка). Некоторыми лингвистами особо отмечается еще так называемая «экспрессивная потребность», т. е. стремление придать какомулибо наименованию большую образность. Еще раз отметим условность и приблизительность такого разделения, так как переосмысление значения отражает сложные когнитивные процессы, в которых также тесно переплетены внешние и внутренние факторы, влияющие на познание действительности и опредмечивание сформированных понятий [1-8].

Прежде всего изменение значения слова вероятно при появлении в жизни общества нового денотата - предмета или понятия. В период становления системы современного английского языка весьма актуальной проблемой была так 
называемая борьба синонимов, когда приходящие в английский язык заимствования вытесняли исконные или пришедшие раньше заимствованные слова в иную сферу. Результатом такой борьбы становились изменения в семантической структуре или стилистической принадлежности обоих слов. Особенно активно этот процесс происходил в средний период. Именно в это время под влиянием заимствованных слов исконные нередко меняли стилистическую принадлежность. Другой лингвистической причиной изменения значения слова считается эллипсис, т.е. сокращение словосочетания, при котором происходит так называемая семантическая конденсация оставшееся слово вбирает в себя смысл всего сочетания.

seggie (заим. из амер.) segregationist «сторонник расовой сегрегации; сегрегационист»;

CGIAR (заим. из амер.) Consultative Group on International Agricultural Research «Консультативная группа nо научным исследованиям в сельском хозяйстве»;

COMAIRCENTLANT(заим. из амер.) Commander, Air Forces, Central Atlantic Subarea«командующий ВВС центрального района Атлантики»;

ComAirFeRon (заим. из амер.) commander, aircraft ferry squadron-«командир авиационной эскадрильи по перегонке самолетов»;

ComAirLant (заим. из амер.) Commander, Air Force, Atlantic Fleet-«командующий авиацией Атлантического флота».

Особое место среди лингвистических причин изменения значения слова занимает сдвиг значения на основе переноса наименования [17,с.78]. Возможность такого переноса кроется в самой сути значения слова, а именно в гибкой связи между такими его компонентами, как понятие и форма. При наличии разных денотатов возможна частичная общность понятия, что отражается в использовании для него старой формы. Виды переноса зависят от типа связей между денотатом и его наименованием. Принято выделять два основных типа таких связей и учитывать их при переводе:

- импликационный (основанный на логической посылке, подразумевающей, имплицирующей связь между частью и целым) DEUCE (заим. из амер.) digital electronic universal computing engine-«универсальная вычислительная машина», COMАВС (заим. из ит) Comitato, per la Difesa Atomica, Biologica e Chimica- «комитет по противоатомной, противобактериологичеекой и противохимической защите»;

- квалификационный (предполагающий наличие общего признака у разных денотатов).

DGIP(заим. из амер.) Division of Global and Interregional Projects -«Отдел глобальных и межрегиональных проектов»,D. О.(заим. из нем) Dienstordnung- «наставление».

Каждый из указанных типов объединяет разные виды переноса. Лексические сокращения после своего создания и начала употребления в речи непосредственно включаются в лексикосемантическую систему языка и подчиняются ее законам.

В процессе функционирования лексические сокращения могут претерпевать различные семантические изменения, не касающиеся во многих случаях семантики исходного полного словосочетания, DNMov(заим. из амер.) Directorate of Naval Movements -«управление перевозок», Dep \& Asst Chief(заим. из амер.) deputy and assistant chief -«заместитель и помощник начальника»,

dep. viv. (заим. из ит) deposito viveri -«продовольственный склад».

Семантические изменения сокращений представляют большой теоретический и практический интерес, однако их изучение, как и любое семасиологическое исследование, сопряжено с многочисленными трудностями, среди которых выделяется, в частности, необходимость учета действия различных факторов. Изучение перевода значений сокращений требует тщательного анализа развития конкретных условий их использования, которые позволяют выявить следующие закономерности:

- сокращенное наименование организации часто может употребляться для обозначения ее члена;

- сокращенное название процесса может употребляться для обозначения устройства, связанного с ним;

- наблюдаются и другие регулярные переносы значения, преимущественно на основе метонимии, имеющие аналогии и в других языках;

- аббревиатуры, как правило, имеют 1-2 значения, если образованы от многозначных исходных полных словосочетаний.

\section{References:}

1. Bezrukova AA (1999) Abbreviaturnye neologizmy-zaimstvovaniya $\mathrm{v}$ russkom yazyke noveyshego vremeni. Vestnik.SamGU. Lingvistika.No.1, pp.17-25.
2. Efremov LP (1974) Osnovy teorii kal'kirovaniya. Alma-Ata:KazakhGU: 198. 
3. Krysin LP (1968) Inoyazychnye slova V sovremennom russkom yazyke. Moscow: Nauka: 208.

4. Murycheva AS (1991) Strukturnofunktsional'nye osobennosti konfrontiruemykh abbreviatur(na materiale anglo-amerikanskoy periodiki): Avtoref.dis.kan.filol.nauk. Moscow: 61.

5. Mogilevskiy RI (1988) Ocherki abbreviatsii slavyanskikh yazykov: Avtoref.dis. dokt.filol.nauk. Moscow: 36.

6. Zemskaya EA (1992) Slovoobrazovanie kak deyatel'nost'. Moscow, Nauka: 222.

7. Bezrukova AA (1999) Abbreviaturnye neologizmy-zaimstvovaniya $\mathrm{v}$ russkom yazyke noveyshego vremeni. Vestnik. SamGU. Lingvistika. No1, pp.17-25.

8. Gorshunov YV (2000) Pragmatika abbreviatury: Avtoref.dis. kand.filol.nauk. Moscow: URSS, 32.

9. Golub IB (2002) Stilistika russkogo yazyka. Moscow: Ayrs-press, 448.

10. Gorshunov YV (2000) Pragmatika abbreviatury: Avtoref.dis.kand.filol.nauk. Moscow: URSS, 32.
11. Grigor'eva OA (2004) Leksika angliyskogo yazyka v tablitsakh. Izdanie - 2e. "Viktoriya plyus", 112.

12. Eliseeva VV (2003) Leksikologiya angliyskogo yazyka. SPb: SPbGU, 280.

13. Katagoshchina NA (1976) Istoriya frantsuzskogo yazyka. Moscow, 280.

14. Kostyashina EA (2008) Funktsional'noe vzaimodeystvie nauchnogo, meditsinskogo i nauchno-populyarnogo diskursov $\mathrm{v}$ tekstovom prostranstve nauchno-populyarnogo meditsinskogo zhurnala. Vestnik Tomskogo gosudarstvennogo universiteta. Filologiya. pp.711.

15. Murycheva AS (1991) Strukturno funktsional'nye osobennosti konfrontiruemykh abbreviatur (na materiale anglo-amerikanskoy periodiki): Avtoref.dis.nand.filol.nauk. Mosk.obl.ped.in-t.im Krupskoy. Moscow, 15.

16. Shapovalova AP (2003) Abbreviatsiya i akronimiya v lingvistike. Nauch. iz-nie. Rostovna-Donu: Izd-vo Rostov.gos.ped.univer, 300.

17. Yashnov PA (2005) Osobennosti perevoda abbreviatur. Moscow: Nauka, pp.77-79. 